\title{
Utilização de frutooligossacarídeo por estreptococos mutans in vitro
}

\section{In vitro utilization of fructooligosaccharide by mutans streptococci}

\author{
Myrna Maria LINARDI* \\ Odila Pereira da Silva ROSA** \\ Marília Afonso Rabelo BUZALAF*** \\ Sérgio Aparecido TORRES***
}

\begin{abstract}
LINARDI, M. M.; ROSA, O. P. da S.; BUZALAF, M. A. R.; TORRES, S. A. Utilização de frutooligossacarídeo por estreptococos mutans in vitro. Pesqui Odontol Bras, v. 15, n. 1, p. 12-17, jan./mar. 2001.

Neosugar é o nome comercial de um frutooligossacarídeo (FOS), cuja utilização por bactérias bucais pouco se conhece. Neste trabalho, avaliou-se o efeito deste produto sobre o crescimento, fermentação e produção de placa in vitro por $S$. mutans sorotipos c, e e f, S. sobrinus, sorotipo d, S. downei, sorotipo h, S. cricetus, sorotipo a e S. rattus, sorotipo b. A avaliação do crescimento foi feita em caldos "Brain Heart Infusion" (BHI) adicionados ou não de sacarose e FOS, e em caldos tamponados contendo glicose ou FOS como fonte de carbono, com inóculos padronizados em espectrofotômetro e leituras das densidades ópticas em 24 horas. Nos mesmos meios, foi feita a leitura do pH, após 24 horas. A placa produzida in vitro em caldos BHI, acrescidos de $5 \%$ de sacarose ou FOS, foi avaliada por meio de pesagem e quantificação de carboidratos e proteínas. Foi comprovada a possivel cariogenicidade do Neosugar, que permitiu o mesmo crescimento e intensidade de fermentação que a sacarose em caldo BHI, de todos os microrganismos e serviu de base para produção de placa in vitro por alguns deles. A quantidade de placa formada e o seu teor de proteínas e carboidratos foram menores que os evidenciados com a sacarose, embora apenas para os últimos tenha sido encontrada diferença estatisticamente significante.
\end{abstract}

UNITERMOS: Streptococcus mutans; Cariogênicos.

\section{INTRODUÇÃO}

Os frutooligossacarideos (FOS) são compostos que ocorrem na natureza e têm sido detectados em várias plantas, como trigo, centeio, cebola, alho, banana, alface, chicória. O Neosugar é uma mistura de frutooligossacarídeos desenvolvido originalmente como adoçante de baixa caloria, não-nutritivo, no Japão. Trata-se de uma mistura de $1^{\mathrm{F}}$-(1- $\beta$-frutofuranosil $)_{\mathrm{n}-1}$-sacarose oligômeros, nos quais $\mathrm{n}$ pode variar de 2 a 4 . Basicamente, são moléculas de sacarose (dissacarídeo glicose-frutose) aos quais foram acrescentadas 1, 2 ou 3 unidades adicionais de frutose por ligação glicosídica $\beta(2 \rightarrow 1)$ às unidades de frutose da sacarose. Esses componentes são abreviados como $\mathrm{GF}_{2}$ (1-kestose), $\mathrm{GF}_{3}$ (nistose) e $\mathrm{GF}_{4}$ (1- $\beta$-frutofuranosilnistose) ${ }^{6}$. Os FOS são produzidos em escala comercial a partir da sacarose, usando uma frutosiltransferase fúngica
( $\beta$-frutofuronidase), produzida naturalmente por Aspergillus niger', ou então a partir da inulina através de hidrólise parcial por endoglicosidase ${ }^{15}$, possuindo cerca de metade do poder adoçante da sacarose. Esses compostos apresentam propriedades físicas que os tornam aplicáveis em produtos alimentícios, como ausência de cor e de odor, estabilidade em $\mathrm{pH}$ neutro e em temperaturas superiores a $140^{\circ} \mathrm{C}$. Como não são digeridos, passam através do intestino delgado sem serem absorvidos e atingem o intestino grosso, onde são utilizados seletivamente por bifidobactérias intestinais. Essas duas características são a chave para sua utilização tendo em vista a saúde humana: alívio da constipação, melhora da composição de lipídeos na corrente sangüínea e supressão da produção de substâncias putrefativas no intestino ${ }^{9}$.

Apesar de haver na literatura vários trabalhos sobre o metabolismo de FOS por bactérias intesti-

* Aluna de graduação e bolsista do PIBIC-CNPq; ** Professora Associada e *** Professores Doutores do Departamento de Ciências Biológicas - Faculdade de Odontologia de Bauru da USP. 
LINARDI, M. M.; ROSA, O. P. da S.; BUZALAF, M. A. R.; TORRES, S. A. Utilização de frutooligossacarídeo por estreptococos mutans in vitro. Pesqui Odontol Bras, v. 15, n. 1, p. 12-17, jan./mar. 2001.

nais, há apenas a pesquisa de HARTEMINK et al. ${ }^{7}$ (1995) que mostra sua utilização por estreptococos bucais, inclusive Streptococcus mutans. Em vista da possibilidade de maior emprego desses compostos, o pouco conhecimento sobre seu potencial cariogênico e a heterogeneidade dos estreptococos do grupo mutans, procurou-se observar o efeito do Neosugar sobre o crescimento, fermentação e produção de placa in vitro, de diferentes representantes desse grupo. Foram utilizadas cepas de referência de $S$. mutans, sorotipos c (GS-5), e (B-2) e f (OMZ-175); S. sobrinus, sorotipo d (SL-1); S. downei, sorotipo $\mathrm{h}(\mathrm{MF}-25) ; \mathrm{S}$. cricetus, sorotipo a (HS-1) e S. rattus, sorotipo b (FA-1). As cepas HS-1, FA-1 e MF-25 foram gentilmente cedidas pelo Prof. Fusao Ota, da Universidade de Tokushima, Japão; as cepas B-2 e OMZ-175, pelo Prof. Jean-P. Klein, da Faculté de Chirurgie Dentaire, Strasbourg, França e as demais cepas pertencem à coleção da Disciplina de Microbiologia.

\section{MÉTODOS}

\section{Avaliação do crescimento e teste de fermentação}

Como inóculo, foram utilizados $50 \mu 1$ de cultivo de 18 horas dos estreptococos do grupo mutans em $5 \mathrm{ml}$ de caldo "Brain Heart Infusion" (BHI, DIFCO), padronizado segundo o padrão 0,5 de McFarland, em espectrofotômetro (PHARMACIA), em $540 \mathrm{~nm}$. Cada cepa foi cultivada em duplicata em cinco meios: caldo BHI, um meio rico, que foi o controle positivo; o mesmo caldo acrescido de $5 \%$ de sacarose (BHI-S) ou frutooligossacarídeo (BHI-FOS); um meio tamponado pobre, contendo glicose (TAMGLICOSE) ou frutooligossacarídeo (TAM-FOS) como fonte de carbono. Todos esses meios foram distribuídos em porções de $4 \mathrm{ml}$ em tubos com tampa de rosca de $13 \times 100 \mathrm{~mm}$, autoclavados a $121^{\circ} \mathrm{C}$, por 15 minutos e submetidos ao teste de esterilidade por 24 horas. O caldo TAM foi constituído por peptona (10 g); $\mathrm{NaCl}$ (5 g); fosfato de sódio dibásico (3,5 g); fosfato de potássio monobásico $(1,5 \mathrm{~g})$; glicose (15 g); extrato de levedura (5 g) e água destilada (q.s.p. $1.000 \mathrm{ml}$ ). O frutooligossacarídeo utilizado nos diferentes meios foi o Neosugar, graciosamente fornecido por Meiji Seika - Japão.

Após receberem o inóculo, os tubos foram incubados a $37^{\circ} \mathrm{C}$, em aerobiose, por 24 horas, fazendo-se a leitura da turvação em espectrofotômetro Ultrospec 1.000 (PHARMACIA) em $540 \mathrm{~nm}$, tendo como controle negativo, para cada meio, um caldo correspondente, sem semear. Logo a seguir, proce- deu-se à leitura do pH em pHmetro (ANALION), para avaliar a fermentação dos açúcares.

\section{Produção da placa in vitro ${ }^{16}$}

Para este teste, foi utilizado o caldo BHI (DIFCO), ao qual foram adicionados $5 \%$ de sacarose ou FOS. Esse meio foi distribuído em volumes de $4 \mathrm{ml}$ em tubos com tampa de rosca de $13 \mathrm{x}$ $100 \mathrm{~mm}$, contendo bengalas de vidro feitas com tubo capilar com 1,5 $\mathrm{mm}$ de diâmetro externo, esterilizado a $121^{\circ} \mathrm{C}$ por 15 minutos e submetido ao teste de esterilidade por 24 horas. Os testes foram feitos em triplicata para cada meio, com incubação a $37^{\circ} \mathrm{C}$ por 24 horas, com transferências diárias para novos caldos, por um período de 5 dias. Como inóculo, foram utilizados $50 \mu 1$ de cultura padronizada conforme descrito para o teste anterior. Para avaliação do depósito, cada bengala de vidro foi mergulhada em tubo de ensaio de $15 \times 125 \mathrm{~mm}$ contendo $8 \mathrm{ml}$ de água destilada esterilizada, para diluição do meio de cultura e remoção do material frouxamente aderido. Em seguida, as bengalas foram transferidas para tubos de ensaio secos e esterilizados para escorrer a água e a placa produzida sobre cada bengala foi recolhida sobre folha de alumínio previamente pesada, utilizando uma espátula, e pesada em balança de precisão (SCIENTECH - precisão 0,0001). Posteriormente, essa placa foi transferida para um frasco tipo penicilina, contendo $\mathrm{NaOH}$ a $50 \%$ e congelada até o momento da quantificação.

Para a quantificação dos carboidratos e proteínas, as suspensões foram descongeladas, colocadas em tubos de ensaio e submetidas à homogeneização manual, com bastão de teflon. A dosagem de carboidratos foi realizada nas amostras em triplicata, de acordo com o método fenol-ácido sulfúrico de DUBOIS et al. ${ }^{4}$ (1956), sendo lida a absorbância em $490 \mathrm{~nm}$ em espectrofotômetro Ultrospec 2.000 (PHARMACIA). A dosagem de proteínas foi realizada em triplicata seguindo o método de LOWRY et al. ${ }^{12}$ (1951), com leituras de absorbância em $660 \mathrm{~nm}$ em espectrofotômetro Ultrospec 2.000 (PHARMACIA). Para obtenção das curvas padrão de referência, foram utilizadas a D-manose e a albumina de soro bovino, respectivamente.

\section{Análise estatística}

O pequeno tamanho da amostra e a grande variabilidade dos resultados levaram à realização de testes não-paramétricos. Para a comparação entre dois grupos, foi utilizado o teste de Wilcoxon e, entre três grupos, a análise de variância de Fried- 
LINARDI, M. M.; ROSA, O. P. da S.; BUZALAF, M. A. R.; TORRES, S. A. Utilização de frutooligossacarídeo por estreptococos mutans in vitro. Pesqui Odontol Bras, v. 15, n. 1, p. 12-17, jan./mar. 2001.

man. Havendo diferença estatisticamente significante nesta última, foi empregado o teste de Dunn para comparações múltiplas. Em todos os casos, foi adotado o nível de significância de 5\%.

\section{RESULTADOS}

Os resultados relativos ao crescimento fornecidos pela leitura da densidade óptica dos caldos, da fermentação, pela leitura do $\mathrm{pH}$, quantidade de placa produzida in vitro e quantidade de carboidratos e proteínas dessa placa são mostrados nas Tabelas 1 a 4 .

A análise estatística demonstrou diferença estatisticamente significante no $\mathrm{pH}$ entre os três caldos $\mathrm{BHI}$, sendo os valores do caldo $\mathrm{BHI}$ maiores que os do BHI-sacarose e BHI-FOS ( $p=0,002)$, os quais não diferiram entre si. A análise também revelou diferença estatisticamente significante na quantidade de carboidrato da placa produzida in vitro, maior no BHI-sacarose que no BHI-FOS $(p=0,043)$. Todas as outras comparações não mostraram diferença estatisticamente significante.

\section{DISCUSSÃO}

Devido às suas propriedades físico-químicas e poder adoçante, os FOS são consumidos principalmente em massas de tortas, confeitos e laticinios ${ }^{6}$. MOLIS et al..$^{14}$ (1996) avaliaram o destino de FOS no trato gastrintestinal em 6 voluntários por 11 dias e observaram que a maior parte dele não foi absorvida no intestino delgado e nenhum foi excretado nas fezes, indicando que a porção que atinge o cólon foi completamente fermentada pela

TABELA 1 - Leitura (densidade óptica) do crescimento das várias cepas bacterianas, nos diferentes caldos, após 24 horas de cultivo.

\begin{tabular}{l|c|c|c|c|c}
\hline \hline $\begin{array}{c}\text { Cepas } \\
\text { (sorotipos) }\end{array}$ & BHI & $\begin{array}{c}\text { BHI- } \\
\text { sacarose }\end{array}$ & $\begin{array}{c}\text { BHI- } \\
\text { FOS }\end{array}$ & $\begin{array}{c}\text { TAM- } \\
\text { glicose }\end{array}$ & $\begin{array}{c}\text { TAM- } \\
\text { FOS }\end{array}$ \\
\hline S. mutans (c) & 1,135 & 0,447 & 1,209 & 0,572 & 0,939 \\
\hline S. mutans (e) & 1,237 & 0,742 & 1,332 & 0,487 & 0,931 \\
\hline S. mutans (f) & 1,412 & 0,643 & 0,642 & 0,570 & 1,193 \\
\hline S. downei (d) & 1,317 & 0,299 & 1,209 & 0,024 & 0,030 \\
\hline S. sobrinus (h) & 1,387 & 1,953 & 1,952 & 1,209 & 1,197 \\
\hline S. cricetus (a) & 1,315 & 1,448 & 1,933 & 0,001 & 0,030 \\
\hline S. rattus (b) & 1,341 & 1,489 & 1,518 & 0,061 & 0,043 \\
\hline Média & 1,306 & 1,003 & 1,399 & 0,418 & 0,623 \\
\hline d.p. & 0,094 & 0,624 & 0,457 & 0,435 & 0,561 \\
\hline \hline
\end{tabular}

$X^{2}=2,00 ; p=0,368 . T=5,00 ; p=0,128$. microbiota local. Concluíram que os FOS são apenas ligeiramente digeridos no intestino delgado e depois fermentados no cólon, resultando em reduzida produção de energia. Particularmente, o Neosugar parece alterar de forma benéfica a microbiota fecal, diminuindo a atividade de algumas enzimas redutoras ${ }^{2}$.

Todos esses fatos positivos chamam a atenção, uma vez que, no Brasil, também se desenvolveu FOS a partir da sacarose, utilizando-se enzima de cepa de Aspergillus niger isolado no país ${ }^{1}$, fato que pode favorecer uma generalização do seu uso e desperta interesse quanto à cariogenicidade desse tipo de produto, mesmo podendo haver diferenças entre FOS de diferentes procedências.

A literatura sobre a utilização de FOS por microrganismos orais limita-se ao estudo de HARTEMINK et al. ${ }^{7}$ (1995), os quais verificaram que a fermentação de FOS por estreptococos orais é muito comum, demonstrando que cepas-estoque de $S$. oralis, S. mitis, S. sanguis, S. gordonii e S. mutans (2 cepas) produziram ácido lático e ácido acético a partir dos oligossacarídeos. Demonstraram também, em teste de acidificação, que a formação de ácido era muito rápida, sendo atingido o $\mathrm{pH}$ crítico dentro de 15 minutos, tanto para a glicose como para o FOS. Os mesmos autores comentam a ampla difusão de estreptococos fermentadores de FOS na população, pois a saliva de quarenta voluntários holandeses, que nunca haviam consumi-

TABELA 2 - Resultados das leituras do $\mathrm{pH}$ das cepas nos diferentes caldos.

\begin{tabular}{|c|c|c|c|c|c|}
\hline $\begin{array}{c}\text { Cepas } \\
\text { (sorotipos) }\end{array}$ & $\mathrm{BHI}$ & $\begin{array}{c}\text { BHI- } \\
\text { sacarose }\end{array}$ & $\begin{array}{l}\text { BHI- } \\
\text { FOS }\end{array}$ & $\begin{array}{l}\text { TAM- } \\
\text { glicose }\end{array}$ & $\begin{array}{l}\text { TAM- } \\
\text { FOS }\end{array}$ \\
\hline S. mutans (c) & 5,4 & 5,0 & 4,2 & 5,3 & 4,7 \\
\hline S. mutans (e) & 5,5 & 4,2 & 4,1 & 4,3 & 4,3 \\
\hline S. mutans (f) & 5,3 & 4,3 & 4,1 & 4,4 & 4,3 \\
\hline S. sobrinus $(\mathrm{d})$ & 5,4 & 4,6 & 4,4 & 6,9 & 6,9 \\
\hline S. downei (h) & 5,4 & 4,2 & 4,2 & 4,4 & 4,5 \\
\hline S. cricetus (a) & 5,8 & 4,5 & 4,2 & 6,9 & 7,0 \\
\hline S. rattus (b) & 5,6 & 4,6 & 4,7 & 6,9 & 6,9 \\
\hline Média & $5,49^{\mathrm{a}}$ & $4,49^{b}$ & $4,27^{b}$ & 5,59 & 5,51 \\
\hline d.p. & 0,17 & 0,29 & 0,21 & 1,27 & 1,33 \\
\hline $\begin{array}{l}\text { Controle } \\
\text { negativo }\end{array}$ & 7,4 & 7,4 & 7,4 & 7,0 & 7,0 \\
\hline
\end{tabular}

$X^{2}=12,07 ; \mathrm{p}=0,002 . \mathrm{T}=4,00 ; \mathrm{p}=0,715$. Grupos com a mesma letra não apresentam diferença estatisticamente significante. 
LINARDI, M. M.; ROSA, O. P. da S.; BUZALAF, M. A. R.; TORRES, S. A. Utilização de frutooligossacarídeo por estreptococos mutans in vitro. Pesqui Odontol Bras, v. 15, n. 1, p. 12-17, jan./mar. 2001.

do FOS comercial, apresentava cepas capazes de degradá-lo. O Streptococcus mutans, um dos estreptococos por eles testados, é a espécie mais prevalente dos estreptococos mutans no homem, tendo sua virulência diretamente associada à disponibilidade de sacarose, que lhe permite a sintese de polissacarídeos extracelulares. Conseqüentemente, o emprego de substitutos da sacarose que não possam ser utilizados da mesma maneira que esse açúcar constitui-se em método eficiente de prevenção da doença.

Ficou patente naquele estudo ${ }^{7}$ que as cepas de Streptococcus mutans parecem variar no modelo de degradação dos constituintes dos FOS. A cepa $\mathrm{n}^{\circ} 36$ rapidamente degradou a nistose, enquanto a cepa $\mathrm{n}^{\circ} 44$ degradou quase todos substratos, exceto a nistose. IKEDA et $a{ }^{10}{ }^{10}$ (1990) mostraram que a nistose era lentamente degradada ou fermentada por 5 cepas de $S$. mutans, entre as quais a NCTC 10449, enquanto ZIESENITZ; SIEBERT ${ }^{18}$ (1987), demonstraram que a nistose era rapidamente degradada pela mesma cepa NCTC 10449. Essas diferenças poderiam ser explicadas pelo fato de a produção de frutanase depender do pré-cultivo e das condições do meio e também porque as frutanases produzidas por diferentes cepas apresentam diferentes preferências por frutanos ${ }^{17}$.

A possivel cariogenicidade do Neosugar, anteriormente prevista ${ }^{7}$, foi comprovada in vitro neste estudo com diferentes representantes do grupo mutans, os quais apresentaram crescimento semelhante em BHI acrescido de FOS ou sacarose, fermentaram na mesma intensidade os dois substratos e utilizaram semelhantemente FOS e glicose, como fonte de carbono (Tabelas 1 e 2).

TABELA 3 - Peso médio (mg) da placa formada in vitro pelas diferentes cepas em dois caldos.

\begin{tabular}{l|c|c}
\hline \hline Cepas (sorotipo) & BHI-sacarose & BHI-FOS \\
\hline S. mutans (c) & 6,0 & 0,7 \\
\hline S. mutans (e) & 16,0 & 7,0 \\
\hline S. mutans (f) & 32,0 & 6,0 \\
\hline S. sobrinus (d) & 5,0 & 5,0 \\
\hline S. downei (h) & 0 & $\mathrm{D}^{*}$ \\
\hline S. cricetus (a) & 57,0 & 33,0 \\
\hline S. rattus (b) & $\mathrm{D}^{*}$ & $\mathrm{D}^{*}$ \\
\hline Média & 16,57 & 7,39 \\
\hline d.p. & 21,09 & 11,67 \\
\hline \hline
\end{tabular}

$\mathrm{T}=0,00 ; \mathrm{p}=0,068 . \mathrm{D}^{*}=$ desprezivel.
O FOS também permitiu a produção de placa, in vitro, em quantidade menor, porém não estatisticamente diferente daquela obtida com a sacarose (Tabela 3). Esse resultado confirma a observação de HARTEMINK et al. ${ }^{7}$ (1995), cuja cepa de $S$. mutans produziu placa de $13 \mathrm{mg}$ após 3 dias com o Neosugar, contra $16 \mathrm{mg}$ frente à sacarose, enquanto no presente trabalho, as quantidades produzidas no BHI-FOS pelos três sorotipos de $S$. $m u$ tans foram de 0,7 (c), 7,0 (e) e 6,0 (f), e no BHI-sacarose, de 6,0, 16,0 e 32,0, respectivamente. Posto que também não tenha sido observada diferença estatisticamente significante para a quantidade de proteína, o teor significantemente menor de carboidratos na placa confirma a tendência notada nas outras quantificações (Tabelas 3 e 4).

A variedade dos resultados com cepas representantes das várias espécies e sorotipos mostra a importância de não se avaliar uma única representante do grupo mutans nesse tipo de pesquisa. Outros trabalhos já evidenciaram diferenças significantes no potencial cariogênico de cepas provenientes de pessoas com diferentes experiências de cáries tanto in vitro ${ }^{13}$ como in vivo $^{11}$. Por outro lado, essa mesma variedade aponta para a influência da composição do meio de cultura sobre esses microrganismos. Um meio que permitiu o crescimento semelhante de todas as cepas, com mínima variação, o BHI (média $\pm d p=1,306 \pm 0,094$ ), quando acrescido de FOS e principalmente de sacarose, influenciou sobremaneira o crescimento dos microrganismos. Isso não se traduziu, porém, em menor

TABELA 4 - Quantidades médias $(\mu \mathrm{g} / \mathrm{ml})$ de carboidratos e proteínas da placa produzida in vitro pelas diferentes cepas em dois caldos.

\begin{tabular}{l|c|c|c|c}
\hline \hline \multirow{2}{*}{$\begin{array}{c}\text { Cepas } \\
\text { (sorotipo) }\end{array}$} & \multicolumn{2}{|c|}{ Carboidratos } & \multicolumn{2}{c}{ Proteínas } \\
\cline { 2 - 5 } & BHI-S & BHI-FOS & BHI-S & BHI-FOS \\
\hline S. mutans (c) & 588 & 258 & 277 & 75 \\
\hline S. mutans (e) & 1.881 & 692 & 254 & 238 \\
\hline S. mutans (f) & 4.096 & 1.156 & 386 & 131 \\
\hline S. sobrinus (d) & 531 & 418 & 216 & 231 \\
\hline S. downei (h) & - & - & - & - \\
\hline S. cricetus (a) & 5.119 & 1.596 & 732 & 304 \\
\hline S. rattus (b) & - & - & - & - \\
\hline Média* & $2.443,0$ & 823,8 & 373,0 & 195,8 \\
\hline d.p. & $2.080,0$ & 549,9 & 210,4 & 91,5 \\
\hline \hline
\end{tabular}

$\mathrm{T}=0,00 ; \mathrm{p}=0,043 . \mathrm{T}=1,00 ; \mathrm{p}=0,079$.

* Não considerando as cepas negativas. 
LINARDI, M. M.; ROSA, O. P. da S.; BUZALAF, M. A. R.; TORRES, S. A. Utilização de frutooligossacarídeo por estreptococos mutans in vitro. Pesqui Odontol Bras, v. 15, n. 1, p. 12-17, jan./mar. 2001.

produção de placa com a sacarose no teste específico.

Considerando-se que a espécie mais prevalente na população é a de S. mutans, torna-se significativo o fato de todos os sorotipos do mesmo apresentarem resultados positivos em todos os testes realizados com o FOS, com eficiência aparentemente maior que a de $S$. sobrinus. Em pesquisa de KÖHLER; KRASSE ${ }^{11}$ (1990), em hamsters, os autores também confirmaram que $S$. mutans foram mais cariogênicos que $S$. sobrinus, diferentemente do observado por EMILSON et al. ${ }^{5}$ (1987), em hamsters, e por DE SOET et al. ${ }^{3}$ (1991), em ratos.

\section{CONCLUSÃO}

Os resultados aqui relatados demonstram a necessidade de se avaliar quaisquer FOS que surjam no comércio quanto ao seu potencial cariogênico, in vitro, sob diferentes condições de cultivo e in vivo.

\section{AGRADECIMENTOS}

Aos laboratórios Meiji Seika, Japão, pela gentil cessão do Neosugar ${ }^{\circledR}$. Ao Prof. Dr. José Roberto Pereira Lauris, pela análise estatística e aos senhores André Luis da Silva e José Osni Vitorato, pelo auxílio técnico.

LINARDI, M. M.; ROSA, O. P. da S.; BUZALAF, M. A. R.; TORRES, S. A. In vitro utilization of fructooligosaccharide by mutans streptococci. Pesqui Odontol Bras, v. 15, n. 1, p. 12-17, jan./mar. 2001.

\begin{abstract}
Neosugar is the trade name of a fructooligosaccharide (FOS) whose utilization by oral bacteria is not well known yet. The aim of the present study was to evaluate in vitro the effect of this product on the growth, fermentation and production of plaque by mutans streptococci: S. mutans, serotypes c, e and f, S. sobrinus, serotype d, S. downei, serotype h, S. cricetus, serotype a and S. rattus, serotype b. The evaluation of growth was carried out in Brain Heart Infusion (BHI) broths containing or not sucrose and FOS and in buffered broths having glucose or FOS as carbon sources, through optical density reading in spectrophotometer after 24 hours of incubation at $37^{\circ} \mathrm{C}$. Thereafter the reading of $\mathrm{pH}$ was made in the same media. The plaque produced on glass sticks in BHI broths containing 5\% sucrose or FOS was weighed and carbohydrates and proteins were assayed. The possible cariogenicity of Neosugar was confirmed, since it sustained the same growth and intensity of fermentation of sucrose in BHI broth for all streptococci and permitted in vitro production of plaque by some of them. The amount of plaque as well as its content of proteins and carbohydrates were smaller than those produced with sucrose, although the difference was statistically significant only for carbohydrates.
\end{abstract}

UNITERMS: Streptococcus mutans; Cariogenicity agents.

\section{REFERÊNCIAS BIBLIOGRÁFICAS}

1. ANDRADE, M. Politicamente correto. Rev Ass Bras Odont, v. 5, n. 3, p. 147, jun./jul. 1997.

2. BUDDINGTON, R. K.; WILLIAMS, C. H.; CHEN, S. C. et al. Dietary supplement of neosugar alters the fecal flora and decreases activities of some reductive enzymes in human subjects. Am J Clin Nutr, v. 63, n. 5, p. 709-716, May 1996.

3. DE SOET, J. J.; VAN LOVEREN, C.; LAMMENS, A. J. et al. Differences in cariogenicity between fresh isolates of Streptococcus sobrinus and Streptococcus mutans. Caries Res, v. 25, n. 2, p. 116-122, Mar./Apr. 1991.

4. DUBOIS, M. et al. Colorimetric method for determination of sugars and related substances. Anal Chem, v. 2, p. 350-356, 1956.

5. EMILSON, C. G.; CARLSSON, P.; BRATTHALL, D. Strains of mutans streptococci isolated in a population with extremely low caries prevalence are cariogenic in the hamster model. Oral Microbiol Immunol, v. 2, n. 4, p. 183-186, Dec. 1987.

6. FISHBEIN, L.; KAPLAN, M.; GOUGH, M. Fructooligosaccharides: a review. Vet Hum Toxicol, v. 30, n. 2, p. 104-107, Apr. 1988.

7. HARTEMINK, R.; QUATAERT, M. C. J.; VAN LAERE, M. J. R. et al. Degradation and fermentation of fructo-oligosaccharides by oral streptococci. J Appl Bacteriol, v. 79 , n. 5 , p. 551-557, Nov. 1995.
8. HIDAKA, H.; EIDA, T. The production of oligosaccharides utilizing sugar transfer action. Bio Industry, v. 1, p. 5-13, 1984.

9. HIDAKA, H.; HIRAYAMA, M. Useful characteristics and commercial applications of fructo-oligosaccharides. Biochem Soc Trans, v. 19, n. 3, p. 561-565, 1991.

10. IKEDA, T.; KURITA, T.; HIDAKA, H. et al. Low-cariogenicity of the tetrasaccharide nystose. Gen Pharmacol, v. 21, n. 2, p. 175-179, 1990.

11. KÖHLER, B.; KRASSE, B. Human strains of mutans streptococci show different cariogenic potential in the hamster model. Oral Microbiol Immunol, v. 5, n. 4, p. 177-180, Aug. 1990.

12. LOWRY, O. H.; ROSEBROUGH, N. J.; FARR, A. L. et al. Protein measurement with the Folin-phenol reagent. J Biol Chem, v. 193, p. 265-275, 1951.

13. MACPHERSON, L. M. D.; MACFARLANE, T. W.; GEDDES, D. A. M. et al. Assessment of the cariogenic potential of Streptococcus mutans strains and its relationship to in vivo caries experience. Oral Microbiol Immunol, v. 7, n. 3, p. 142-147, Jun. 1992.

14. MOLIS, C.; FLOURIE, B.; OUARNE, F. et al. Digestion, excretion and energy value of fructooligosaccharides in healthy humans. Am J Clin Nutr, v. 64, n. 3, p. 324-328, Sept. 1996.

15. NORMAN, B. E.; HOJER-PEDERSEN, P. The production of fructooligosaccharides from inulin or sucrose using 
LINARDI, M. M.; ROSA, O. P. da S.; BUZALAF, M. A. R.; TORRES, S. A. Utilização de frutooligossacarídeo por estreptococos mutans in vitro. Pesqui Odontol Bras, v. 15, n. 1, p. 12-17, jan./mar. 2001.

inulinase or fructosyltransferase from Aspergillus ficcum. Denpun Kagaku, v. 36, p. 103-111, 1989.

16. OLIVEIRA, C. M.; ARAUJO, W. C. Formação de placa in vitro em culturas puras de Streptococcus isolados de pacientes. Rev Bras Odontol, v. 25, n. 149, p. 270-276, jan./fev. 1968.
17. WALKER, G. J.; HARE, M. D.; MORREY-JONES, J. G. Activity of fructanase in batch cultures of oral streptococci. Carbohydr Res, v. 113, n. 1, p. 101-112, Feb. 1983.

18. ZIESENITZ, S. C.; SIEBERT, G. In vitro assessment of nystose as a sugar substitute. J Nutr, v. 117, n. 5, p. 846-851, May 1987.

Recebido para publicação em 15/06/00 Enviado para reformulação em 25/11/00 Aceito para publicação em 15/12/00

Estética: Recursos Atuais da Dentística para o Clínico Ministradores: Prof. Dr. José Fortunato F. Santos e equipe Teórico-clinico-demonstrativo Carga horária: 96 horas

Periodo de realização: 14/03 a $27 / 06 / 2001$

Horário: $4^{\text {as }}$ feiras das $17 \mathrm{~h}$ às 22h30

Valor: R\$ 50,00 de inscrição e 4 mensalidades de $\mathrm{R} \$ 300,00$

\section{Odontopediatria na Primeira}

Infância - Orientação à

Gestante, Prevenção e

Tratamento de Bebês de Zero

\section{a 5 Anos}

Ministradoras: Profa. Dra. Maria Salete Nahás Pires Corrêa, Profa. Flavia Ribeiro de Carvalho Fernandes, Profa. Luciana Fazzi e Profa. Mariângela Schalka

\section{Teórico-clínico}

Módulo I

Carga horária: 90 horas/aula (teórico-prático)

Período de realização: 14/03 a $11 / 07 / 2001$

Horário: $4^{\text {as }}$ feiras das $14 \mathrm{~h}$ às $18 \mathrm{~h}$ e eventualmente das $18 \mathrm{~h}$ às $20 \mathrm{~h}$

Valor: R\$ 50,00 de inscrição e 4 mensalidades de $\mathrm{R} \$ 300,00$

\section{Módulo II}

Carga horária: 90 horas/aula (prático - com complementação teórica)
Periodo de realização: 01/08 a 05/12/2001

Horário: $4^{\text {as }}$ feiras das $14 \mathrm{~h}$ às $18 \mathrm{~h}$ e eventualmente das $18 \mathrm{~h}$ às $20 \mathrm{~h}$ Valor: R\$ 50,00 de inscrição e 4 mensalidades de $\mathrm{R} \$ 300,00$

Módulo III - Aperfeiçoamento clínico

Requisitos: Módulos I e II

Carga horária: 90 horas/aula

Período de realização: 14/03 a

$11 / 07 / 2001$

Horário: $4^{\text {as }}$ feiras das $14 \mathrm{~h}$ às $18 \mathrm{~h}$ Valor: R\$ 50,00 de inscrição e 4 mensalidades de $\mathrm{R} \$ 300,00$

\section{Workshop - Utilização Clínica do Laser}

Ministradores: Prof. Dr. Carlos de Paula Eduardo e equipe

Carga horária: 20 horas/aula

Periodo de realização: 15, 16 e 17/03/2001; 07, 08 e 09/06/2001; 20, 21 e 22/09/2001; e 22, 23 e 24/11/2001

Horário: $5^{\mathrm{a}}$ e $6^{\mathrm{a}}$ feiras das $8 \mathrm{~h}$ às $18 \mathrm{~h}$ horas e sábado das $8 \mathrm{~h}$ às $12 \mathrm{~h}$

Valor: 1 mensalidade de

$\mathrm{R} \$ 450,00$

Obs.: O aluno poderá escolher o período que mais lhe convier.

\section{Dor Orofacial - Soluções para o Clínico Geral}

Ministrador: Prof. Dr. Marcelo Bolzan
Teórico-clínico

Carga-horária: 64 horas/aula

Periodo de realização: 16/03 a 29/06/2001

Horário: $6^{\text {as }}$ feiras das $14 \mathrm{~h}$ às $18 \mathrm{~h}$ Valor: R\$ 50,00 de inscrição e 4 mensalidades de $\mathrm{R} \$ 300,00$

\section{Endodontia}

Coordenação: Prof. Assoc. Antonio Carlos Bombana e Prof. Dr. Celso Luiz Caldeira

Assistência: Prof. Weber Bueno de Andrade e Prof. Oscar Faciola Pessoa

Carga horária: 64 horas $180 \%$ clínico)

Periodo de realização: 16/03 a 29/06/2001

Horário: $6^{\text {as }}$ feiras das $8 \mathrm{~h}$ às $12 \mathrm{~h}$ Valor: R\$ 50,00 de inscrição e 4 mensalidades de $\mathrm{R} \$ 300,00$

\section{Ortodontia - Pequenos Movimentos Ortodônticos para o Clínico Geral}

Ministrador: Prof. Dr. Jorge Abrão Teórico-laboratorial

Carga horária: 64 horas

Periodo de realização: 16/03 a 29/06/2001

Horário: $6^{\text {as }}$ feiras das $19 \mathrm{~h}$ às $23 \mathrm{~h}$ Valor: R\$ 50,00 de inscrição e 4 mensalidades de $\mathrm{R} \$ 350,00$

Continua na página 63. 